\title{
Reality TV in the digital era: a paradox in visual culture?
}

\section{Arild Fetveit}

UNIVERSITY OF OSLO

It's like they say. The picture's worth a thousand words. The video camera's worth a million words really. (Police officer in Real TV)

More real than the real, that is how the real is abolished. (Jean Baudrillard)

The advent of digital manipulation and image generation techniques has seriously challenged the credibility of photographical discourses. ${ }^{1}$ At the same time, however, we are experiencing a growing use of surveillance cameras, and a form of factual television that seems to depend more heavily on the evidential force of the photographic image than any previous form: reality $T V$.

The simultaneity of the digital 'revolution in photography' (Ritchin, 1990) and the proliferation of visual evidence seems paradoxical. It seems as if we are experiencing a strengthening and a weakening of the credibility of photographical discourses at the same time. How are we to make sense of this? Are we, in some sense, at a turning point in visual culture? And, if so, does this entail a strengthening or a weakening of the evidential credibility of photographical images? Or, is there a third option available? The aim in this article is to historicize and conceptualize this possible change in visual culture, and to suggest plausible explanations for the proliferation of reality TV in the digital era.

I shall begin by presenting a conceptual framework for assessing changes in credibility for photographical discourses, before historicizing this credibility briefly. Then I move on to the use of visual evidence in reality TV, and the impact of digitalization. I conclude by suggesting some explanations concerning the initial paradox, the most important one emphasizing the increasingly discourse-specific trust in photographical images, and

Media, Culture \& Society (C) 1999 SAGE Publications (London, Thousand Oaks and New Delhi), Vol. 21: 787-804 [0163-4437(199911)21:6;787-804;010765] 
consequently, the need to complement a general technical understanding of photographical images with knowledge of different photographical practices.

\section{Histories of photographical images}

In order to suggest a conceptual framework for understanding changes in the credibility of discourses based upon photographical images, I find it useful to look at an argument advanced by John Tagg (1988), and later developed by Martin Lister (1995). These writers warn against placing too much emphasis on the common characteristics of photographical images. Rather than thinking of photography as a singular medium with unifying characteristics, they encourage us to recognize that there are numerous uses of photography, and that the medium changes significantly according to the discourse it is used within. Presenting Tagg's view, Lister claims that

... it is more helpful to think of 'photographies' which have different 'histories' than it is to think of a singular medium with a singular, grand and sweeping history. The conventional history of photography has been written like The History of Literature or Art. It would be better understood as like a history of writing. By which Tagg means that it is better understood as a technique which is employed in many different kinds of work. (Lister, 1995: 11)

I think Tagg and Lister are right in warning against a too monolithic view of photographical images. A view that is too heavily based upon unique technical features will tend to neglect the amount of convention invested in photographical practices. However, the reverse danger also exists. By emphasizing issues of convention too strongly, the unique iconical/indexical relation to the profilmic - which prepares the ground for the use of photographical evidence - is overlooked. Tagg makes himself guilty of this in claims like the following: 'That a photograph can come to stand as evidence ... rests not on a natural or existential fact, but on a social, semiotic process' (1988: 4). This conventionalism dismantles any idea of a common technological core unifying photographical practices in different areas. It dissolves photography into a set of faintly related conventional practices constituted by the different conventions at work in the various fields of use.

I want to argue that we should neither opt for a wholesale technologically and existentially based view, nor a wholesale conventionalist one. Rather, we ought to see photographical practices as fundamentally based upon existential features involving the iconical/indexical relation to the profilmic, but also as strongly invested with conventions. Further, we should be aware that to the extent to which we believe in a common core in photography, changes in our trust in one type of photographical discourse might affect our trust in another. Thus, digital manipulation of photographical images within one area might not only affect our trust within that 
particular area, it might also lead to a declining trust in other uses of photographical images, and to an undermining of credibility for photographical discourses in general. The picture I am drawing here is one in which we can conceive of trust in discourses based upon photographical images as existing on two levels:

- trust in discourses based upon photographic images in general;

- trust in specific discourses based upon photographical images: documentary film; nature photography; reality TV; news photography; photography used in advertising, etc. ${ }^{2}$

This general framework for writing on the history of photographical images suggests that we can write both the history, and histories of photography and moreover, it suggests that relationships between these levels might be interesting to explore. It should also be noted that in our understanding of photographical discourses, a historical shift of balance between these two levels is conceivable. At one point in time we may think of photographical practices as fairly unified, but the development of more diversified practices may prompt us to ask questions of trust on a more discourse-specific level.

Before coming to the present changes in credibility, I shall present a brief account of some earlier changes in this field. Hopefully, this might give a better background for understanding the present situation.

\section{The growth of credibility}

A suitable point of departure would be 1839, when the techniques of two of the inventors of photography, William Henry Fox Talbot and Louis Jacques Mandé Daguerre, were first disclosed. Both viewed photography as a tool that was able to produce visual evidence. Talbot characterizes photographical images as unique, since they 'have been obtained by the mere action of Light upon sensitive paper. They have been formed or depicted by optical and chemical means alone, and without the aid of anyone acquainted with the art of drawing' (1844: unpaginated). They are unique, he adds, since an effect is produced 'having a general resemblance to the cause that produced it'. Talbot is thereby prefiguring present semiotic conceptions of photography as based upon an iconic/indexical relation to the thing photographed. He goes on to suggest that the images might be accepted in court as 'evidence of a novel kind'. This view parallels that of Daguerre's representative, the physicist M. François Arago, who argued that the French government should purchase Daguerre's patent on the grounds of its artistic and scientific uses. He argued that the camera would join 'the thermometer, barometer, and hygrometer' (quoted in Arago, 1980: 
23), as well as the telescope and microscope, as scientific instruments, and that it will provide 'faithful pictorial records' of events (1980: 17). Although early photography was first of all used for making portraits, the evidential power of these images was not neglected. This is apparent not least in the early portraits of criminals. ${ }^{3}$

According to Tagg, a considerable change due to technical development occurred towards the end of the century.

In the decades of the 1880 s and the 1890 s . . photography underwent a double technical revolution, enabling, on the one hand, the mass production of cheaply printed half-tone block and, on the other hand, the mass production of simple and convenient photographical equipment, such as the hand-held Kodak camera. (Tagg, 1988: 66)

Kodak provided a light and inexpensive camera. The half-tone plates which were introduced enabled the mass production of photographs in books, magazines and newspapers. Both prepared the ground for an increased use of the camera for purposes of surveillance. ${ }^{4}$ However, it is important to keep in mind that the early introduction of double exposure, composite images and other photographic tricks prefiguring film effects made for a complicated field, where both issues of what photography should be and issues of its evidential quality were contested. ${ }^{5}$

Though the technical means for using photography in books and magazines were available, according to André Bazin, a 'feeling for the photographic document developed only gradually' (1967: 11). He supports this claim by pointing to the rivalry between photographic reporting and the use of drawing in the illustrated magazines of 1890-1910, with drawings often preferred on account of their dramatic character. The notion that a feeling for the photographic document developed gradually is interesting. One way to think of this is that there was an increasing emphasis on the documentary or evidential quality of the images, adding to their illustrative qualities. Another way to conceive of this development would be to see it as a result of a gradual adoption of the photographical technology within new areas. This cumulative adoption within different areas of use might then effect a strengthening of the general credibility of photographical evidence. Thus, we get interplay between a discourse-specific level and a general level, as suggested in the framework above.

The invention of cinema in the 1890s adds new dimensions to the array of visual evidence: time and movement. However, it also invites fictional uses where the evidential, in a sense, is relieved. Without going into the complexities of this, let me just point to some major turns in the development of visual evidence within film. Though the first films derived much of their appeal from the sheer fascination with authentic footage, the first powerful interest for the evidential seems to evolve in the 1920s with Dziga Vertov's programme for a 'true cinema', Kino Pravda. In a reaction to fiction, the 
lives of the people were to be caught 'unawares'. Still, Vertov was criticized for not going far enough, since he edited his films in a way that made it difficult to identify time and place of the events filmed. In 1926, Viktor Shklovsky said that 'newsreel material is in Vertov's treatment deprived of its soul - its documentary quality' (1988a: 152). He also complained that

... there is no precise determination of the [shots].... The man who departs on broad skis into the snow-covered distance is no longer a man but a symbol of the departing past. The object has lost its substance and become transparent, like a work by the Symbolists. (1988b: 153)

This critique eloquently illustrates a possible spectrum open to actuality footage between the illustrative and symbolic, on the one side, and the evidential, on the other. Later changes in the view of credibility can be understood partly in view of such a spectrum.

Though the term 'documentary film' suggests a genre based on the documentary power of photographical images, manipulations, recreations and fakeries were prevalent in these films throughout the 1930s (see Barnouw, 1984). Thus, the illustrative and symbolic function of the images was dominant. After the Second World War, however, actuality material was strongly preferred over dramatizations (perhaps due to the impact of the authentic war footage; see Bazin, 1967: 155-6). Thus, the evidential function of the images was considerably strengthened.

Prefiguring today's reality TV, an even stronger emphasis on the evidential comes with the advent of lightweight camera equipment featuring synchronic sound recording in the late 1950s. ${ }^{6}$ Increased camera access allies with an epistemological optimism to establish a new documentary aesthetic, strongly based upon observation and interviews, often documenting events as they unfold through an 'objective', 'fly on the wall' technique. ${ }^{7}$ On the face of it, much of today's reality TV seems to redeem aspirations both from Vertov's Kino Pravda to catch life 'unawares', and from the verité movements of the 1960s to give an objective view of life as it unfolds. Thus, the evidential aspirations of photographical discourses are powerfully carried on - if not stretched to their limits - in reality TV.

I have suggested that a belief in the evidential powers of photographical images might grow through (1) the adoption of photographical techniques in novel areas and through (2) the shift of emphasis from the illustrative to the evidential power of the images used. The history of photography is filled with examples of the first; the adoption of photography in illustrated magazines (as pointed to by Bazin) being just one of them. The latter movement is exemplified in the critique of Vertov, and, later, in the growing demands for authenticity within documentary film, first after the Second World War, then with the coming of lightweight equipment. Though photomontage, retouch and other non-evidential manifestations of 
photography have been around since the first days of photography, in general, I think it is fair to say that the evidential view of photography has gained a strong position through the years. However, inherent in the very fabric of photographical images seems to lie an unresolvable tension between the illustrative and the evidential, the iconic and the indexical and it is within this very fabric that digital manipulation and reality TV now seem to confront each other. The advent of the former exerts a pull in the direction of the illustrative and the iconic, the latter in the direction of the evidential and the indexical.

\section{Visual evidence in reality TV}

Concepts like 'reality TV', 'reality show', 'reality programming' and 'neoverité' have been used to designate this recent trend in television, showing us dramatic moments from police work, rescue operations, accidents, etc. ${ }^{8}$ COPS and LAPD show us police at work; programmes like Crimewatch $U K$ recreate unsolved crimes in order to enlist the audience as assistants to the police; ${ }^{9}$ I Witness Video and Real TV show dramatic (and sometimes funny) moments caught on tape. Though some of the reality TV programmes employ recreations - notably Rescue 911 and Crimewatch UKmost rely on visual evidence of the following kinds:

- authentic footage from camera crews observing arrests or rescue operations;

- footage from surveillance videos;

- recordings (often by amateurs) of dramatic accidents and dangerous situations.

Both COPS and $L A P D$ are based on the recordings of a one-camera unit 'riding along' with the police in the patrol car. The chaotic and rough sound track, saturated with white noise from police radios and accidental environmental sounds, testifies to the authenticity of the recordings, as does the ragged movements of the hand-held camera. The footage in COPS is further authenticated by a voice-over in the opening of the programme claiming that 'COPS is filmed on location with the men and women of law enforcement'. In long takes, displaying the action as it unfolds, we are presented with chases, arrests and police inquiries. Though the camera has good access to the events, we might still have a hard time figuring out what is happening through sheer observation. This is solved by having one police officer brief another in front of the camera. In $L A P D$, voice-over narration is also used.

Formats that rely on amateur and surveillance videos are often structured around a single and unique moment caught by camera: a dramatic car crash, a 
robbery caught by a surveillance camera or even aeroplanes colliding in mid air. This moment, when 'real TV happens', as the announcer in Real $T V$ phrases it, is the evidential jewel around which the segment is built. ${ }^{10}$ The dramatic footage is often supported by testimonies from people involved. In most cases we get an account from the surviving victim looking back at the incident. We can also find interviews with friends and family, with accidental eyewitnesses and in some cases with police or rescue workers. These elements surround and explain the dramatic footage. Repetition and slow motion are often used to help us inspect the visual evidence.

In an episode from the Norwegian version of Real TV, we see amateur videos from an air display featuring two MIG 29s doing impressive loops. ${ }^{11}$ When the aeroplanes demonstrate a twin loop, they get too close, and the wing of the leader slices the other plane. As the planes collide, we hear the narrator of Real TV say: 'During a fatal moment, the overwhelming view of the two gracious aeroplanes is transformed into an inferno in the air. The cameras capture every single moment.' Then, we meet two eyewitnesses. First, the speaker of the air display comments on the accident as we see it once more: 'In a fraction of a second, these two graceful jets were flaming pieces of rubbish, falling out of the sky.' Then, a clip from an interview with a firefighter is inserted, in order to remind us of the danger, and to prolong the suspense: 'Looking at the state of the wreckage - if you would have been in there, there wouldn't have been a lot left of you', he says. We see the crash again, this time in slow motion and from a slightly different angle, as the narrator comments 'but in this video you can see the pilots eject themselves the second after the collision'. Two circles are drawn above the planes in order to guide our vision. We can faintly see two dots shooting out from the planes, before we see the parachutes opening, bringing the pilots safely to the ground. ${ }^{12}$

Here the evidential power of the cameras that are capturing 'every single moment' has become the main issue. The focus is not so much on presenting a story of an air crash, as on presenting the audio-visual evidence showing us what really happened in that decisive moment when the planes crash. The function of the camera is close to that of the scientific instrument, measuring out the concrete details of a particular instant. The format heavily propagates a belief in visual evidence. However, the strong presence of verbal elements pointing out what is going on in the footage, should not be neglected. The 'visual evidence' is not merely visual. Walter Benjamin makes an interesting prediction when commenting on increased camera access in the 1930s:

The camera will become smaller and smaller, more and more prepared to grasp fleeting, secret images whose shock will bring the mechanism of association in the viewer to a halt. At this point captions must begin to function.... Will not captions become the essential component of pictures? (Benjamin, 1980: 215) 
Benjamin's observation on the relationship between the visual and the verbal is surprisingly well fitted to reality TV featuring authentic recordings of dramatic events. Many of the blurred and chaotic images at the height of drama seem to need powerful support from linguistic sources for us to make sense of them. The description of what we see helps us to choose the suitable level of perception; it helps to focus, not simply our gaze, but also our understanding. ${ }^{14}$

The focus on presenting the audio-visual evidence as much as 'the story' is one of the features that distinguishes reality TV from earlier attempts to 'catch the real'. This focus also leads to an emphasis on the visible surface of the world rather than on deeper symbolic aspects. Whereas Vertov set out 'to fix and organize the individual characteristic phenomena of life into a whole, an extract' (1988: 115) - reality TV will opt for an exploration of the visible surface of the here and now, avoiding abstract, symbolic montage and often pointing to its own status as visual evidence. The goal is 'to capture that Real TV moment', and audience members are advised to keep a camcorder in the trunk of their cars because, you 'never know when real TV might happen' ${ }^{15}$ Similarly, the producers of COPS are looking for 'amazing, unusual, exciting or weird videotapes. Crazy arrest, angry suspects, hot pursuits and bloopers from in car cameras' (sic). ${ }^{16}$ What we get is evidential photography paired with an aesthetics of 'liveness', a dramaturgy geared towards keeping alive the question, 'What happens next?', and often 'Will the good guys make it?', 'Will the bad guys fry?', then, the putatively objective eye of the camera provides the answer for us to see. And the TV channel will not let us have serious doubts: 'yes, they will'. ${ }^{17}$ Our two pilots survived against all odds, and thereby inscribed themselves into the mythic core of reality TV. The deepest fascination with the evidential - when slow motion and repetition serve a close scrutiny of the footage - seems to occur when death is only inches away.

Nonetheless, how can this almost frantic obsession with the evidential powers of the camera survive in a digital era? Does not digitalization do away with visual evidence?

\section{Digitalization and visual evidence}

Photographical images cannot account for their own production process very eloquently; they cannot tell us where, when and how they are taken. Though we are often successful in our guesses on issues like these, our only way of knowing is by way of a truthful account from the producer or some other person who knows. Any serious use of visual evidence has to rely on such knowledge. This means that, in order to work, visual evidence is reliant upon more or less explicit verbal descriptions and personal/ institutional warrant that the descriptions hold true. Provided that this is 
taken care of, that the technology works and the people using it are doing what they are supposed to, cameras will still serve their purposes in monitoring us on the street, in the bank, in prison or surveilling physical experiments in the sciences or the inside of our bodies under surgery.

Whereas descriptions of images used for scientific purposes will tend to be explicit, standardized and detailed, the opposite is normally the case for images used in the media. Here we are informed about the status of the recordings either through genre convention, or through channel and programme style. Our belief that television news mainly features authentic recordings, and that some channels will tend to stick more firmly to such a policy than others, is established this way. Claims might also be more explicitly stated, like the claim that COPS is 'filmed on location', or that we see 'the pilots eject themselves the second after the collision' in a Real $T V$ episode. In the last case we get an interpretation of the footage and no explicit statement about its authenticity, since this is regarded as selfevident. However, later developments within digital techniques have made such assumptions less evident.

The development of computer programs for manipulation and generation of images has made it, at times, very hard to see whether we are looking at ordinary photographical images or images that have been digitally altered. In the latter case, iconicity is sustained, whereas indexicality - the causal relation between the profilmic (what was in front of the camera) and the image - is partly disappearing. In most cases it will still be there, but we might have a hard time deciding which parts of an image originate from the profilmic event, and which parts are digitally generated or manipulated. Thus, the evidential power of composite and digitally manipulated images is practically lost. It is also important to note that digitalization has substantially expanded the spectrum of photographical techniques available - especially within the increasingly blurred boundaries between painting and photography - though the different practices employed may not be detectable in the images themselves. This makes us more heavily reliant upon the truthfulness of the claims made about photographical images. ${ }^{18}$

We should also note that the impact of 'the digital revolution in photography' is contingent upon the use of these techniques within different areas. In some areas digital manipulation techniques are used extensively, in other areas such techniques are more or less banned. People engaged in the production of factual discourses like news and documentary tend to shy away from digital imagery, whereas those who create commercials and fiction films employ such techniques more freely. Negotiating institutional standards is an important part of adapting to the new situation. Such negotiations have taken place in the press, in television news and within nature photography, just to mention a few areas. ${ }^{19}$ Some argue pragmatically that what is important is that the truth be told, not whether the images are authentic or have been subjected to colour adjustments or removal of 
disturbing objects, etc. Others seem to think that any conduct transgressing what goes on in a traditional darkroom setting will ruin the credibility, not only of the images, but also of what is being told.

There have been efforts to communicate the status of the images explicitly by marking manipulated images with ' $\mathrm{M}$ ', but it seems that a more implicit communication has gained the upper hand. There might be limits to the audiences' interest in metacommunication, and besides, arguments have also been advanced against the ' $M{ }^{\prime}{ }^{20}{ }^{20}$ Following other factual discourses, producers of the reality TV formats discussed here are also careful not to give the impression that their programmes have been subjected to image manipulation or that they contain footage that is not authentic. ${ }^{21}$

More research on these institutional negotiations would be welcome. What are the arguments used? Where are the limits drawn? How do agents position themselves in order to protect the credibility of their discourse and distance themselves from less credible discourses? It would also be interesting to know more about how changes in one discourse may bleed over and affect another, or affect the credibility of photographical discourses on a more general level. ${ }^{22}$

I shall leave these questions now, and turn to some less palpable dimensions of this change within visual culture.

\section{A psychological loss}

The dissemination of indexicality does not only represent an undermining of evidential power. On a deeper psychological level, I shall argue that it also might come to represent a loss of contact with the world. This is because photographical images come with a promise to provide a certain sense of connectedness. By way of the light rays emanating from the person photographed, the image becomes inscribed with traces from that person: it becomes a relic. As Bazin puts it, a 'transference of reality from the thing to its reproduction' takes place (1967: 14). And more than sheer information, what we seem to be attracted to in these images is a form of presence.

A very faithful drawing may actually tell us more about the model but despite the promptings of our critical intelligence it will never have the irrational power of the photograph to bear away our faith. ... No matter how fuzzy, distorted, or discoloured, no matter how lacking in documentary value the image may be, it shares, by virtue of the very process of its becoming, the being of the model of which it is the reproduction; it is the model. (Bazin, 1967: 14)

This deep psychological fascination with the sense of connectedness, of closeness to something infinitely remote, is also what Barthes takes as his point of departure in Camera Lucida (1981). Looking at a photograph of 
Napoleon's youngest brother, Jerome, taken in 1852, Barthes realizes with amazement: 'I am looking at eyes that looked at the Emperor' (1981: 3). This sense of connectedness (which in Barthes's phrasing above makes the representation disappear and replaces it with the object itself) is an important source of fascination with photographical images. When indexicality is disseminated, this sense of connectedness is also partly lost.

Pursued to a more global level, this is a loss concerning our sense of contact with reality through audio-visual representations. Within a McLuhanesque understanding, the media are 'extensions of man', prosthetic devices that extend our perceptive apparatus. From this perspective, the loss of indexicality could be interpreted as a powerful refiguration of these extensions, implicating our perceptive apparatus. In this refiguration, representations based upon the iconic/indexical are being replaced by representations sustaining the iconic, but losing the causal connection to reality. Thus, to the extent that indexicality is lost, we might not only lose evidential power, we might come to feel a sense of losing touch with reality, like being stranded in the world of the simulacrum.

\section{From technological to institutional trust}

In view of all this, how can we conceive of our initial paradox, the simultaneous loss of faith in photographical images and the proliferation of reality TV and visual evidence? Rather than a general strengthening or weakening of the evidential credibility of photographical images, I think we are witnessing an increased compartmentalization of credibility; a shift of emphasis from general assessments of credibility, to more discoursespecific judgements. I am not claiming that a compartmentalized understanding of photographical images is something entirely new, but I believe it is currently being strengthened. A move in our understanding of photography from a general and technically defined level, to a more discoursespecific level reliant upon discourse-specific practices and institutional warrant, permits the coexistence of reality TV and digital manipulation, since different discursive practices are guided by different rules.

This brings us back to Tagg and Lister. If we regard our initial paradox as solved, I think it is at the price of accepting that the common technological core unifying photographical images across different formats and practices has become less important to us. Thus, our understanding of these images has moved some steps in the direction Tagg and Lister are suggesting. With increasingly different practices, now encouraged by the advent of digital techniques, our understanding of and trust in photographical images must more than ever take varying practices and conventions into account. Thus, the credibility of photographical discourses becomes 
less reliant on an overarching trust in the technology of photography and more dependent upon institutional warrant.

This compartmentalization may go a long way in explaining why the coexistence of digital manipulation and reality TV is no contradiction in terms, but it does not provide any explanation for the obsession with visual evidence and reality expressed in reality TV. Obviously, institutional changes and economical drives should not be forgotten, but I also think the interest in reality TV is feeding upon less tangible aspects of the current changes.

\section{The ambiguous longing for the real}

In a deeper psychological sense, the proliferation of reality TV could be understood as an euphoric effort to reclaim what seems to be lost after digitalization. ${ }^{23}$ And what seems lost is not only a belief in the evidential powers of photography, but as much a sense of being in contact with the world by way of indexicality. The powerful urge for a sense of contact with the real is inscribed in much of the reality TV footage. The rough quality of the hand-held footage draws attention to the issue of contact itself, to what Jakobson (1988) calls the phatic function of discourse.

The reality depicted in these formats is most of the time one where other lives are at stake; either people survive accidents that could have been fatal, or the real-life danger is provided by police hunting assumed criminals. What most powerfully conveys a sense of reality is, perhaps, the presence of death. It is also where the real ends. In a sense, death cannot be represented, but still we cannot stop representing it. ${ }^{24}$ On reality TV, however, death is almost only depicted when the surviving numbers are astonishing. After all, a major theme in these programmes seems to be the good citizen escaping death, and the bad citizen being confined.

Reality TV comes with a unique promise of contact with reality, but at the same time it promises a secure distance. Too much reality is easily dispensed with by a touch on the remote control. It is not reality, it is reality $T V$, reality show. Kevin Robins points to a 'tendency to replace the world around us with an alternative space of simulation' (1996b: 159). He sees reality TV as 'anticipating, ahead of any technological transformation, the experience of ... virtual-reality systems' (1996a: 121-2). He develops this comparison by maintaining that virtual reality 'is inspired by the dream of an alternative and compensatory reality ... so attractive because it combines entertainment and thrills with comfort and security' (1996a: 122).

These perspectives suggest a rather complex scenario in which developments in visual culture interact with both technical and sociopolitical issues. From this perspective, digital manipulation hardly represents any threat to reality TV, since both bring us closer to simulation anyway, 
though admittedly in different ways. I think this analysis is suggestive, particularly the sociological and political perspectives that it yields. It points to an increasing compartmentalization of society in which we build up 'safe environments' where we no longer need to share physical room with the underprivileged, where the more problematic aspects of reality are locked out. With its focus on rescuing us from nature and technology gone astray, and protecting us from criminals, reality TV could easily be interpreted as conveying an ideology tailored to such a development.

However, I think we should hesitate somewhat in plainly talking about 'simulation', both in regard to digitized photography and reality TV. A partial loss of indexicality does not bring about a state of simulation, at least not in the sense of a generalized suspension of referentiality. After all, the referential image was not invented by Talbot and Daguerre, though, admittedly, their effort of bringing together the iconical and the indexical has powerfully come to shape what we understand by 'representing reality'. Furthermore, rather than simply claiming that reality TV represents simulation, I suggest that we should see it as a representation of reality which is not very useful for developing our understanding of what goes on in the world.

What is at stake here, it seems to me, could be reconceptualized as a tension between modes of representation, modes that reflect different views on what reality is, or, perhaps more precisely, different views on which aspects of reality should be represented. Shklovsky, in his critique of Vertov, wanted less symbolism and general statements and more concrete accounts. Reality TV seems to have taken us further in such a direction than we have ever been before. Now Robins, however, in the tradition of Plato, Brecht, Benjamin and others, wants to take us back. This seems like an ongoing struggle within the very fabric of photography - reflecting a similar tension within our understanding of reality - where no level between the symbolic and the concrete is 'the right one', except according to the purposes and interests we might have. However, in a situation where the critical and independent documentary is having a hard time competing with more flashy reality-oriented programming, it should be in our interest not to allow reality TV too much influence on what 'reality' should be on our television screens. ${ }^{25}$

\section{Conclusion}

I have been arguing that the coexistence of digital manipulation and visual evidence testifies to a transmutation within our visual culture. This is a change in which the credibility of photographical images has become less dependent upon technology and more based upon institutional warrant. Thus, we have recently seen efforts to negotiate and communicate standards 
for photographical discourses. These changes require us to place greater emphasis on the differences between photographical practices, and less upon the technical features that unite them. Such a move, from the idea of trust as linked to the technology itself and towards placing it in a larger technoinstitutional complex, largely resolves our initial paradox originating from the simultaneous proliferation of digital imagery and visual evidence.

I have suggested that reality TV, itself, might be read partly as a symptom of unsettled issues in this transmutation. More precisely, it might express a longing for a lost touch with reality, prompted by the undermining and problematizing of indexicality. Not only does reality TV powerfully reclaim the evidential quality of photography said to be lost after digitalization, it also seems to be obsessed with conveying a sense of connectedness, of contact with the world $-\mathrm{a}$ trait that also, albeit on a less tangible psychological level, might seem to be lost in an era where silicon has replaced the silver of Daguerre and Talbot.

\section{Notes}

Thanks to Rådet for anvendt medieforskning, Handlingsplanen mot vold i bildemediene and Institusjonen Fritt Ord for supporting my research on reality TV financially. I also want to thank Arnt Maas $\varnothing$, Andrew Morrison, John Corner, James Friedman, Carol J. Clover and Kiersten Leigh Johnson for helpful comments and suggestions.

1. The reason why I prefer talking about the credibility of 'photographical discourses' rather than 'photographical images' is that it makes no sense to say that an image as such is credible or not. Only when the image is used within a discursive context does it make sense to talk about credibility.

2. This picture could be rendered in several different ways. For example, we could easily add a third level here: either technologically based (photography, film, television, computer) or based on cultural function (entertainment, information).

3. It is hardly surprising that the possibilities of the new instrument were soon discovered by the legal apparatus. Photographic documentation of prisoners became institutionalized in the 1860s (Sekula, 1993), and the Paris police were using cameras eagerly in the round-up of Communards in June 1871 (Sontag, 1979: 5). A substantial growth in the uses of photographical evidence by the police follows the development of Sir Edward Henry's system of identification by means of fingerprints in 1901. It soon became apparent that the only way to record fingerprints discovered at the scene of a crime was by way of photography (Tagg, 1988: 75-6).

4. Tagg argues that the 'democratization' and proliferation of photography following this 'double technical revolution', set the stage for a far-reaching pictorial revolution: 'the political axis of representation had been entirely reversed. It was no longer a privilege to be pictured but the burden of a new class of the surveilled' (1988: 59).

5. James Lastra points to debates about whether "combined negatives of two or more exposures might still be considered "photographs", in light of the prolifera- 
tion of single-exposure snapshots' (1997), citing titles like 'Combination Printing: Is it Legitimate in Photography?' (Burton, 1893) and 'Are Composite Photographs Typical Pictures?' (Bowditch, 1894). Issues of veracity were also raised at the time in articles like 'Are Instantaneous Photographs True?' (Abney, 1889).

6. This is not the first time sound plays an important role in bringing film closer to tangible reality. With the advent of sound, newsreels like Fox's Movietone News were praised for bringing the world closer, and Warners' Jazz Singer (1927) for bringing new life to the screen. However, the coming of sound was also heavily deplored by people like Pudovkin, Eisenstein and Arnheim, who felt that the highly developed abstract and symbolic montage of the silent film was threatened by the blunt closeness to reality brought about by sound.

7. Brian Winston sees this as a very unfortunate development: 'A hundred and thirty years or so after François Arago claimed the camera for science, the documentary purists, essentially American direct cinema proponents, implicitly reasserted that claim on behalf of the lightweight Auricon and the Eclair. In such hands the camera was nothing more than an instrument of scientific inscription producing evidence objective enough to be "judged" by a spectator' (1995: 151). The problem with this, as Winston further argues, is that research, analysis and social meaning are abandoned in favour of 'emotionalism and aesthetic pleasure' (1995: 154).

8. Intimate talk shows are also often referred to as 'reality TV'. Though they obviously form part of a general turn towards 'reality' within television entertainment, I prefer reserving the term for programmes depicting physical drama on location, rather than emotional drama produced in the studio. See Richard Kilborn (1994) for a broader survey of this turn towards 'reality' in television programming.

9. The format used in Crimewatch $U K$ is employed in local productions throughout the Nordic countries. The various programs are called Øyenvitne (Norwegian TV2), Station 2 (Danish TV2), Efterlyst (Swedish TV 3), Polisii TV (Finnish YLE TV 2).

10. Real TV, which in Norway is broadcast as Fra Virkeligheten (TV2), also contains more evolving events with longer takes, as did its predecessor I Witness Video, in Norway called Videovitne (TVNorge). However, these more slowly evolving segments, containing the rescue of animals or showing people doing 'weird' things, do not raise issues of evidence in the same way as the dramatic footage of possible death (which most of the time turn out to be footage of survival).

11. Broadcast by Norwegian TV2, on 5 March 1998. In the Norwegian version, the host, John Daly, is replaced by Richard Kongsteien (who used to host Øyenvitne).

12. Though our attention is first and foremost directed towards the visual elements, excerpts of authentic sound might also become the focus of special attention, though this is rather uncommon. In the example above, as the planes collide, we hear a vague sound, a bit like voices. The speaker says: 'That's the sound of 150,000 people drawing their breath in, and gasping at what they've seen, myself included.'

13. Working from similar assumptions as Benjamin's, Roland Barthes develops the concepts 'anchorage' and 'relay' when trying to describe the function of the linguistic message with regard to the iconic. When the linguistic message is dominating, Barthes talks of 'anchorage'. When the iconic and the linguistic are equally important, the linguistic message functions as a 'relay'. He further claims that 'in every society various techniques are developed intended to fix the floating chain of signifieds in such a way as to counter the terror of uncertain signs; the linguistic message is one of these techniques' (1977: 39). 
14. The use of replay and slow motion is perhaps greater in sports than any other programming. Decisive moments of failure or achievement can be experienced again and again, extracted from the normal flow of time and projected into the sphere of slow motion for detailed scrutiny and aesthetic admiration. Another place where the aesthetics of slow motion is prevalent is in ultra-violent film scenes. Now, reality TV seems able to provide a common ground here, bringing sport, violent events and visual evidence together. Our present example, the MIGs crashing in an air display, comes close to a merger of these elements.

15. URL: http://www.realtv1.com/ (15 Feb. 1997).

16. URL: http://www.tvcops.com/page_cops.html (15 Feb. 1997).

17. In the formats where the material has been edited, keeping in line with channel policy represents no problem. Another matter is live reports. In early May 1998, BBC International reported a problem for American television channels as a car chase ended brutally. In front of a live television audience, a man killed his dog and set his truck on fire before blowing his head off with a shotgun. This episode might induce a change in policy when it comes to transmitting live from such events.

18. There is again (see note 5 above) some hesitation towards using the term 'photography' in relation to digitally manipulated images, but though concepts like 'hyper-photography', 'post-photography' and 'digital photography' have been introduced, I believe the established designations are likely to prevail. More specified designations, as well as metacommunication about how the images were produced, will first of all be required when the audience is frustrated, or when those making the images want to distinguish their practices from others.

19. Whereas discussions within news departments seem to be reasonably settled (with a slightly more conservative result in print media than within television), debates within nature photography might not be that settled. The March/April 1997 issue of American Photography ran a discussion about the norms of photography related to Barbara Sleeper and Art Wolfe's book Migrations: Wildlife in Motion (1994) where Wolfe has digitally enhanced about one-third of the pictures. $\mathrm{He}$ claims it is art, while his critics call it fake documentation.

20. Søren Kjørup argues against the marking of manipulated images since this might support unrealistic beliefs in the evidential power of other images (1993).

21. The importance of authenticity was strongly emphasized in a personal interview with John Langley, the executive producer of COPS (4 March 1997). The same attitude was expressed by Andrew Jebb, producer of $L A P D$, in a personal interview (3 March 1997). It is further interesting to note that Jebb gave a substantially lower estimate of the amount of 'B-roll' (footage that is not authentic) used than his co-workers did in a less formal meeting (same date). This illustrates the importance for these producers to underline the 'realness' of their products.

22. The proliferation of digitized imagery within advertising does not seem to affect our trust in documentary photography too much. But when many of the discourses involving photographical images start using digital techniques, I believe our general trust might be affected - also our trust in documentary photography.

23. Jean Baudrillard talks about a 'Panic-stricken production of the real and of the referential' when the simulacrum replaces referential discourses (1994: 7).

24. As Vivian Sobchack says, 'nonbeing is not visible. It lies over the threshold of visibility and representation. Thus, it can only be pointed to.... The classic "proof" of the excess of death over its indexical representation was the fascination exerted by the Zapruder film of John Kennedy's assassination; played again and again, slowed down, stopped frame by frame, the momentum of death escaped each moment of its representation' (1984: 287). Nonetheless, as Bill Nichols 
indicates, we don't give up: 'at death's door, we find documentary endlessly, and anxiously, waiting. It hovers, fascinated by a borderzone it cannot ever fully represent' (1994: 48).

25. John Corner (1995, 1996), Richard Kilborn (1998) and Richard Kilborn and John Izod (1997) give fuller assessments of how commercial pressures and 'reality'-orientation affect current documentary production.

\section{References}

Abney, W. de W. (1889) 'Are Instantaneous Photographs True?', International Annual of Anthony's Photographic Bulletin 2: 256-7.

Arago, François Dominique (1980) 'Report', pp. 15-25 in Alan Trachtenberg (ed.) Classic Essays on Photography. New Haven, CT: Leete's Island Books.

Barnouw, Eric (1984) Documentary: A History of the Nonfiction Film. Oxford: Oxford University Press.

Barthes, Roland (1977) 'Rhetoric of the Image', in Image, Music, Text. London: Fontana.

Barthes, Roland (1981) Camera Lucida: Reflections on Photography. New York: Hill \& Wang.

Baudrillard, Jean (1994) Simulacra and Simulations. Ann Arbor: University of Michigan Press.

Bazin, André (1967) What is Cinema?, Vol. 1. Berkeley: University of California Press.

Benjamin, Walter (1980) 'A Short History of Photography', pp. 199-216 in Alan Trachtenberg (ed.) Classic Essays on Photography. New Haven, CT: Leete's Island Books.

Bowditch, H.P. (1894) 'Are Composite Photographs Typical Pictures?', McClure's Magazine 3 (Sept.): 331-4.

Burton, W.K. (1893) 'Combination Printing: Is it Legitimate in Photography?', Pacific Coast Photographer 2(5): 318-20.

Corner, John (1995) Television Form and Public Address. London: Edward Arnold.

Corner, John (1996) The Art of Record: A Critical Introduction to Documentary. Manchester: Manchester University Press.

Jakobson, Roman (1988) 'Lingustics and Poetics', in David Lodge (ed.) Modern Criticism and Theory: A Reader. London: Longman.

Kilborn, Richard (1994) "How Real Can You Get?": Recent Developments in "Reality" Television', European Journal of Communication 9: 421-39.

Kilborn, Richard (1998) 'Shaping the Real: Democratization and Commodification in UK Factual Broadcasting', European Journal of Communication 13(2): 201-18.

Kilborn, Richard and John Izod (1997) An Introduction to Television Documentary: Confronting Reality. Manchester: Manchester University Press.

Kjørup, Søren (1993) 'Billedmanipulation: Og den indexikalske teori om fotografiet', in Jostein Gripsrud (ed.) Mediegleder. Oslo: Ad Notam Gyldendal.

Lastra, James (1997) 'From the Captured Moment to the Cinematic Image: A Transformation in Pictorial Order', pp. 263-91 in Dudley Andrew (ed.) The Image in Dispute: Art and Cinema in the Age of Photography. Austin: University of Texas Press.

Lister, Martin (1995) 'Introductory Essay', in The Photographical Image in Digital Culture. London: Routledge. 
Nichols, Bill (1994) Blurred Boundaries: Questions of Meaning in Contemporary Culture. Bloomington: Indiana University Press.

Ritchin, Fred (1990) In Our Own Image: The Coming Revolution in Photography. New York: Aperture.

Robins, Kevin (1996a) Into the Image: Culture and Politics in the Field of Vision. London: Routledge.

Robins, Kevin (1996b) 'The Virtual Unconscious in Postphotography', pp. 154-63 in Timothy Druckrey (ed.) Electronic Culture: Technology and Visual Representation. New York: Aperture.

Sekula, Alan (1993) 'The Body and the Archive', pp. 342-88 in Richard Bolton (ed.) The Contest of Meaning: Critical Histories of Photography. Cambridge, MA: MIT Press.

Shklovsky, Viktor (1988a) 'Where is Dziga Vertov Striding?', pp. 151-2 in Richard Taylor and Ian Christie (eds) The Film Factory: Russian and Soviet Cinema in Documents 1896-1939. Cambridge, MA: Harvard University Press.

Shklovsky, Viktor (1988b) 'The Cine-Eyes and Intertitles', pp. 153-4 in Richard Taylor and Ian Christie (eds) The Film Factory: Russian and Soviet Cinema in Documents 1896-1939. Cambridge, MA: Harvard University Press.

Sleeper, Barbara and Art Wolfe (1994) Migrations: Wildlife in Motion. Hillsboro, OR: Beyond Words Publishing,

Sobchack, Vivian (1984) 'Inscribing Ethical Space: Ten Propositions on Death, Representation, and Documentary', Quarterly Review of Film Studies 9(4): 283-300.

Sontag, Susan (1979) On Photography. New York: Penguin Books.

Tagg, John (1988) The Burden of Representation: Essays on Photographies and Histories. London: Macmillan.

Talbot, William Henry Fox (1844) The Pencil of Nature. London: Longman, Brown, Green \& Longmans.

Vertov, Dziga (1988) 'Fiction Film Drama and the Cine-Eye: A Speech', pp. 115-16 in Richard Taylor and Ian Christie (eds) The Film Factory: Russian and Soviet Cinema in Documents 1896-1939. Cambridge, MA: Harvard University Press.

Winston, Brian (1995) Claiming the Real: The Documentary Film Revisited. London: British Film Institute.

Arild Fetveit is Research Fellow at the Department for Media and Communication, University of Oslo, and is currently a Visiting Scholar at the Department of Rhetoric, University of California, Berkeley. He has worked within reception studies, reality TV and digitalization of film and photography. Now he is writing a book on the problem of defining documentary and the discursive possibilities in-between documentary and fiction.

Address: Department of Media and Communication, University of Oslo, PO Box 1093 Blindern, 0317 Oslo, Norway. [email: arild.fetveit@media. uio.no] 